\title{
Interrogative Design in Experimental Course: A Case Study of Mobile Graffiti Projection Mapping Design
}

\author{
Yun-Ju Chen ${ }^{1, \mathrm{a}}$; Yi-Lung Lin ${ }^{2, \mathrm{~b}} ;$ Ya-Kuan Chou ${ }^{3, \mathrm{c}}$; Ping-Yeh Li ${ }^{4, \mathrm{~d}^{*}}$ \\ ${ }^{1}$ Department of Interactive Entertainment Design, China University of Technology; Hsinchu Campus: No. 530, Sec. 3, \\ Zhongshan Rd., Hukou Township, Hsinchu County 303, Taiwan, R.O.C. \\ ${ }^{2}$ Department of Interactive Entertainment Design, China University of Technology; Hsinchu Campus: No. 530, Sec. 3, \\ Zhongshan Rd., Hukou Township, Hsinchu County 303, Taiwan, R.O.C. \\ ${ }^{3}$ Department of Interior Design, China University of Technology; Hsinchu Campus: No. 530, Sec. 3, Zhongshan Rd., Hukou \\ Township, Hsinchu County 303, Taiwan, R.O.C. \\ $4 *$ (Corresponding Author) Department of Art and Design, National Taipei University of Education; No.134, Sec. 2, Heping E. \\ Rd., Da-an District, Taipei City 106, Taiwan, R.O.C. \\ ayjchen@cute.edu.tw, ${ }^{\mathrm{b}}$ lineno@cute.edu.tw, ${ }^{\mathrm{c}}$ miaululumi@yahoo.com.tw, ${ }^{\mathrm{d}}$ pingyehli@gmail.com
}

\begin{abstract}
"Interrogative Design in Experimental Course" is a cross-disciplinary curriculum based on the approach of "Interrogative Design" from MIT Media Lab. The course aim of making and presenting "interrogative design works" is to raise questions through art and design, addressing any issues regarding to the campus in order to initiate discussions and draw public attention.
\end{abstract}

Key words: interrogative design, mobile graffiti, projection mapping, experimental teaching

\section{Introduction}

Originating from relatively simple slide projections in the early 1980 s, the video projection mapping used today is very popular among artists and media professionals, becoming a common type of artistic technique and equipment. For multimedia installations, indoor or outdoor performing arts, this important format can often be found as an integral part of cultural, political and commercial activities. However, video projection mapping is more often carried out in public outdoor spaces. In addition to its ornamental and spectacle features, the projections themselves have the ability to transform physical space and time, allowing viewers to enter a transitional, psychological, and intermediary space as well as latent issues to be presented and explored. Therefore, using projection as a medium for changing the quality of a space can not only helps preserve the physical, cultural, and historical significance of a space/building, but also potentially raises a dialogue with the space across a virtual medium. This is the biggest feature of video projection mapping. The author is also exploring the possibility of this application in experimental teaching and research.

The objective of this course is to construct a work through Mobile Graffiti Projection Mapping with Interrogative Design as its core concept. Through the design of the course, students will learn to use light sculpture software and technology to complete a light sculpture project. Through design and artistic techniques, it proposes critical questions regarding campus issues, guiding students to pathways for alternative thinking and practice, enhancing the interaction between the university and the local community, establishing a symbiotic link between the school and the community, and teaching students how to play the role of a social citizen. It creates an opportunity for universities, teachers and students to dive into local issues, and actively participate in and practice "University Social Responsibility."

\section{Relevant Research}

\section{A. Interrogative Design}

Interrogative: 1. Of, pertaining to, or of the nature of questioning; having the form or force of a question. 2. Of a word or form employed in asking questions [1].

Krzysztof Wodiczko, who teaches at the Massachusetts Institute of Technology, opened a high-level workshop "Interrogative Design Workshop" for graduate students in 2002, focusing on those who are striving to break their silence in order to interrupt the world around them in an empowered critical voice. Participants will learn how to conceive and develop communicative equipment, programs and environments to inspire and assist those who are asserting their communicative rights in physical and digital public space.

Wodiczko considering that among these potential "speakers" are those survivors of present-day injustice whose ability to communicate must first be recovered or developed, the design concepts may need to respond not only to ethico-political demands, but also to psychological conditions. How can art, design and technology contribute to fearless speech in light of these contexts? More specifically, how can artists, engineers, and scientists, operating physically and on-line within the fields of industrial design, digital communications, wearable media, performance, critical public art, media art, fashion design and other fields inspire, give a presence to, empower and protect fearless speakers? The other context of this workshop is an increasing public focus on trauma, memory and testimony and insufficient focus on the struggle for social justice through critical truth-telling and outspokenness (parrhesia) [2].

\section{B. Projection Mapping}


Projection mapping, similar to video mapping and spatial augmented reality, is a projection technology used to turn objects, often irregularly shaped, into a display surface for video projection. These objects may be complex industrial landscapes, such as buildings, small indoor objects or theatrical stages. By using specialized software, a two- or three-dimensional object is spatially mapped on the virtual program which mimics the real environment it is to be projected on. The software can interact with a projector to fit any desired image onto the surface of that object [3]. The first known instance of projection onto a non-flat surface dates back to the opening of Disney's Haunted Mansion ride in 1969. The ride featured singing busts, which were created by shooting actors singing on $16 \mathrm{~mm}$ film and then projecting the shots back onto busts of their faces [4]. The next projection mapping instance comes in 1980, with the immersive film installation Displacements by Michael Naimark. In this art installation a living room with two performers were filmed with a rotating camera, then the camera was replaced with a projector. The result is rotating projection mapping [5].

Projection mapping started to progress after researchers at the University of North Carolina at Chapel Hill began working with projection in a 3D environment to build an "Office of the Future." Theoretically, the office would use projectors and synchronized cameras to capture the geometry and reflectance information of surfaces in the office. This information would be used to create a graphical display environment and 3D tele-immersion capabilities that would allow distant people to feel as though they are together in a shared office space [6]. After "The Office of the Future," UNC Chapel Hill began to explore projecting textures onto 3D objects, such as a model of the Taj Mahal, and dynamic shader lamps (a projection-based augmented reality system), which allowed them to paint on moveable objects. They also began experimenting with moveable projectors for the potential use of warehouse inventory [7].

\section{Research Method and Teaching Design}

\section{A. Research Method}

This experimental course will use collaborative action research method. Collaborative action research is one of the forms of action research [8]. Based on the action research method proposed by Lewin (1946), it aims to explore the course of practical work and is a way to combine research and action. Lewin developed a theory of action research as a spiral of steps involving planning, fact-finding (or reconnaissance) and execution, and which later came generally to be understood as an action-reflection cycle of planning, acting, observing and reflecting (Fig. 1) [9].

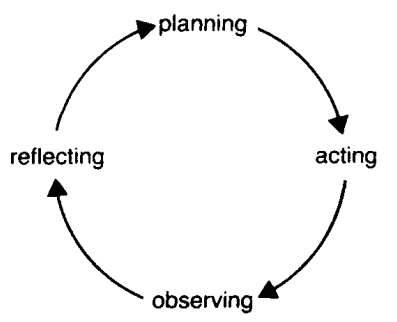

Fig. 1 Action-reflection cycle

\section{B. Teaching Design}

"Interrogative Design" is a method of observing and asking questions about local social phenomena in the field by cross-disciplinary art and design, and publishing it in public. I hope to develop a new dialogue mechanism through the way of Interrogative art and design.

The course will be conducted in four phases: First, grouped in groups of five, through the comprehensive exploration of the campus outdoor public space in the field, the initial exploration of the use of the public space of the university campus is carried out, and the public field of the production and publication of the work is pre-explored, and how to use the space that has been taken for granted through the projection mapping to converted into transitional intermediary space, to reflect of the hidden issues in the depths of the history of the space cultural significance. Second, using the projection mapping software and technologies acquired in the course, let the student focus on the campus issues, will integrate the mobile projection equipment or build a mobile projection vehicle, and then publishing projection mapping works in campus's public place. Third, projection artwork needs to be published in the public space of the campus to rethink the order and system of public space in daily life, and to learn the ability to discuss and communicate with the audience on-site. Four, this course requires the transformation or construction of mobile projection equipment, or the construction of mobile projection vehicles, such as tricycles, recycling vehicles, carts, bicycles, luggage, backpacks, helmets and other mobile vehicles, etc., which will develop students' ability to make mobile vehicles.

\section{Observation and Results}

The four groups were observed and graded during the creation process. Grading Final Projects, the teachers assessed the following four abilities for "Explores Issue", "Works Concept", "Research and Reference" and "Critique and Reflects" with four parts different grades by: 1 (Bad), 2 (Acceptable), 3 (Good), 4 (Very Good), and provided the main reason (Why). This research's observation was documented as follow:

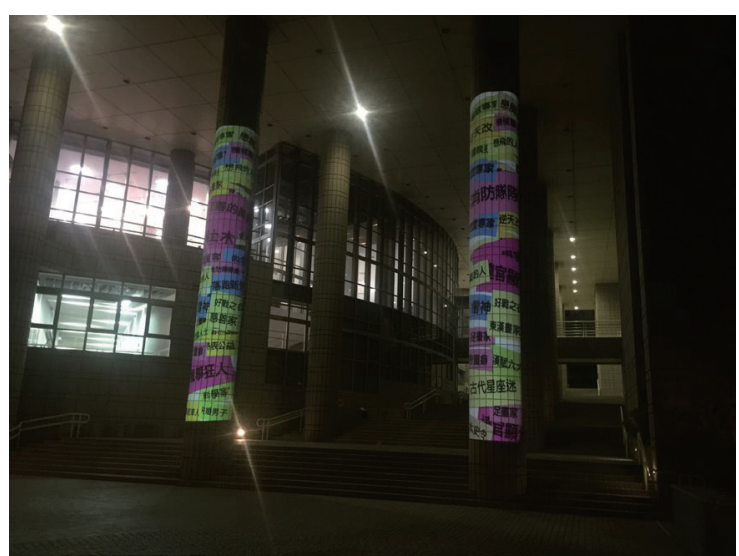

Fig. 2 Design Work by Group A

A. Group A:

1. Topic: Tag Day

2. Questioning question: Is it really good for the general public to classify others with specific impressions such as academic diploma and social status, and label them with specific labels? 
3. Grading:

(1) Explores Issue: 4 (Very Good). Use a variety of media, techniques, and processes or communicate their own experiences and ideas effectively.

(2) Artwork Concept: 3 (Good). Projection location, techniques and tools used, event planning and artistic concept are in a safe and responsible manner.

(3) Research and Reference: 4 (Very Good). Utilize a variety of resources to research and enhance their artwork including technology, print, event and first hand art experiences.

(4) Critique and Reflects: 1 (Bad). The criticality of the issue is not strong enough.

(5) Total Points (Overall Assessment): 12.

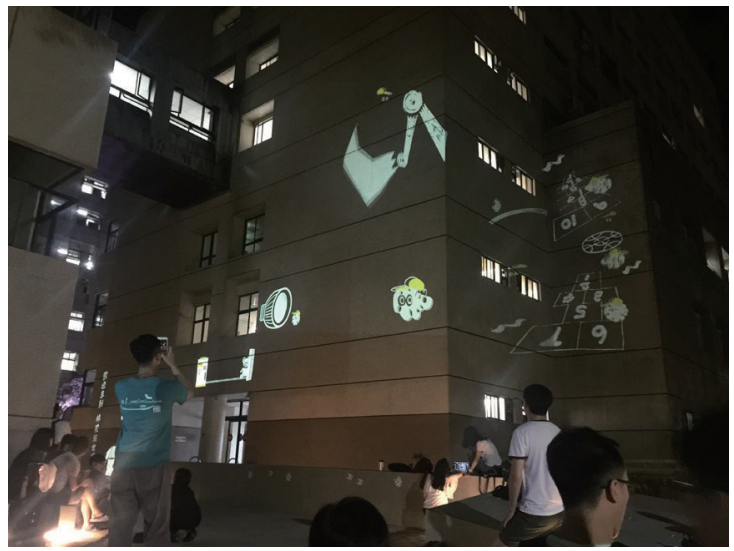

Fig. 3 Design Work by Group B

\section{B. Group B:}

1. Topic: Cotton generation

2. Questioning question: Education has shaped us into a society that has entered a society after a series of educational systems. But can this kind of cramming education help us integrate into society?

3. Grading:

(1) Explores Issue: 4 (Very Good). Use a variety of media, techniques, and processes or communicate their own experiences and ideas effectively.

(2) Artwork Concept: 4 (Very Good). Courage to challenge the techniques and tools used, as well as perfect projection location, event planning and artistic concept.

(3) Research and Reference: 4 (Very Good). Utilize a variety of resources to research and enhance their artwork including technology, print, event and first hand art experiences.

(4) Critique and Reflects: 2 (Acceptable). Express the criticality of the issue.

(5) Total Points (Overall Assessment): 14.

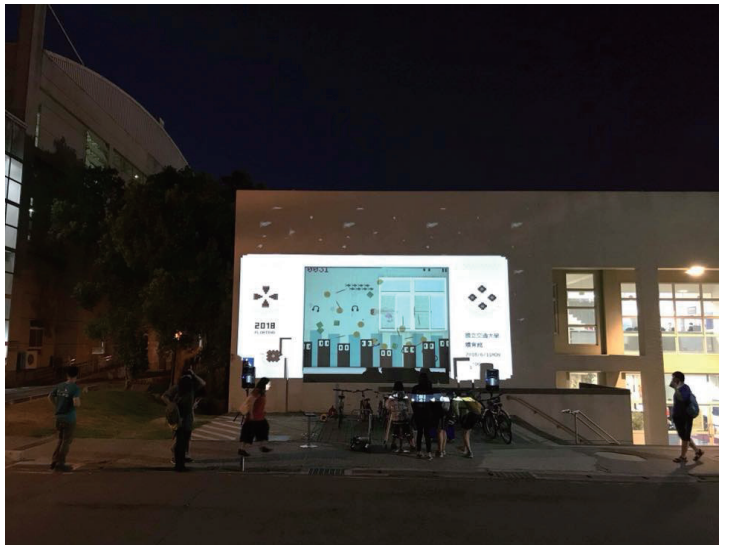

Fig. 4 Design Work by Group C

\section{Group C:}

1. Topic: FLOATING

2. Questioning question: We are constantly being defined as what kind of person we should be, should be like this, should be like that, but we can never follow our own heart. Where will our future drifting?

3. Grading:

(1) Explores Issue: 2 (Acceptable). The concept of idea is hard to understand, the teacher helped provide some necessary information or clarified ideas.

(2) Artwork Concept: 4 (Very Good). Courage to challenge the techniques and tools used, as well as perfect projection location, event planning and artistic concept.

(3) Research and Reference: 4 (Very Good). Utilize a variety of resources to research and enhance their artwork including technology, print, event and first hand art experiences.

(4) Critique and Reflects: 2 (Acceptable). Express the criticality of the issue.

(5) Total Points (Overall Assessment): 12.

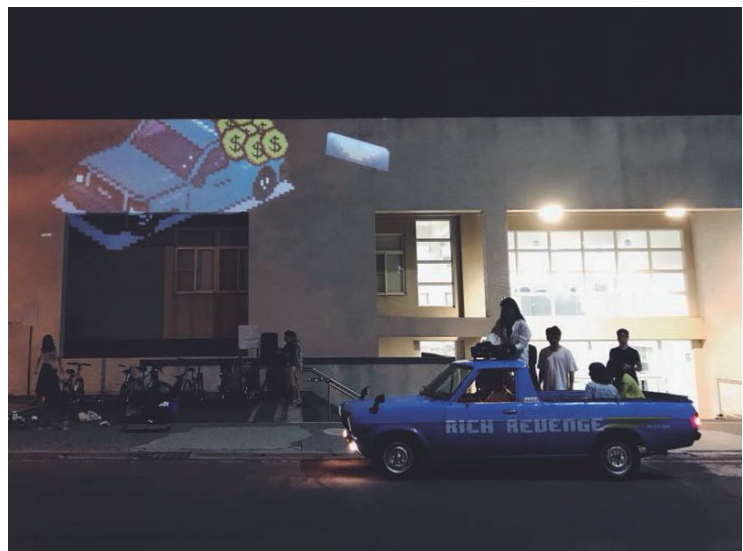

Fig. 5 Design Work by Group D

\section{Group D:}

1. Topic: Rich Revenge

2. Questioning question: In today's society, "wealth" is equivalent to social status. This forces us to think about the connection between money and the future. Is the rich person a successful people?

3. Grading:

(1) Explores Issue: 4 (Very Good). Use a variety of media, techniques, and processes or communicate their own 
experiences and ideas effectively.

(2) Artwork Concept: 4 (Very Good). Courage to challenge the techniques and tools used, as well as perfect projection location, event planning and artistic concept.

(3) Research and Reference: 4 (Very Good). Utilize a variety of resources to research and enhance their artwork including technology, print, event and first hand art experiences.

(4) Critique and Reflects: 3 (Good). Express critical issues and make people think about issues.

(5) Total Points (Overall Assessment): 15.

TABLE I

Grading result of the Final project

\begin{tabular}{|c|c|c|c|c|}
\hline & Group A & Group B & Group C & Group D \\
\hline $\begin{array}{l}\text { Explores } \\
\text { Issue }\end{array}$ & $\begin{array}{c}4 \\
\text { (Very Good) }\end{array}$ & $\begin{array}{c}4 \\
\text { (Very Good) }\end{array}$ & $\begin{array}{c}2 \\
\text { (Acceptable) }\end{array}$ & $\begin{array}{c}4 \\
\text { (Very Good) }\end{array}$ \\
\hline $\begin{array}{l}\text { Artwork } \\
\text { Concept }\end{array}$ & $\begin{array}{c}3 \\
\text { (Good) }\end{array}$ & $\begin{array}{c}4 \\
\text { (Very Good) }\end{array}$ & $\begin{array}{c}4 \\
\text { (Very Good) }\end{array}$ & $\begin{array}{c}4 \\
\text { (Very Good) }\end{array}$ \\
\hline $\begin{array}{l}\text { Research } \\
\text { and } \\
\text { Reference }\end{array}$ & $\begin{array}{c}4 \\
\text { (Very Good) }\end{array}$ & $\begin{array}{c}4 \\
\text { (Very Good) }\end{array}$ & $\begin{array}{c}4 \\
\text { (Very Good) }\end{array}$ & $\begin{array}{c}4 \\
\text { (Very Good) }\end{array}$ \\
\hline $\begin{array}{c}\text { Critique } \\
\text { and Reflects }\end{array}$ & $\begin{array}{c}1 \\
(\mathrm{Bad})\end{array}$ & $\begin{array}{c}2 \\
\text { (Acceptable) }\end{array}$ & $\begin{array}{c}2 \\
\text { (Acceptable) }\end{array}$ & $\begin{array}{c}3 \\
\text { (Good) }\end{array}$ \\
\hline Total Points & 12 & 14 & 12 & 15 \\
\hline
\end{tabular}

The results of the scoring are not intended to illustrate the good or bad of the artwork. This course emphasizes students' ability to train students' questions and critical thinking through "Interrogative Design" methods to gain a deeper understanding of local social issues. With the unfolding of this experimental teaching praxis, the participants, questions raised, works produced, and the discussions, presentations, and documentaries that have been made will contribute to the construction of the strategy of interrogative design within Taiwan's socio-historical context. This will be one of the significances and contributions of this research.

\section{Conclusions}

The content of this experimental course consists of innovative design, starting with related software operations and the installation of mobile vehicles for the projection equipment. This course enables students to bring up social issues they care about through the development of dynamic image design and installation of mobile projection equipment. Utilizing design and artistic techniques, they will be able to present their concerns and questions visually in a public space through the light sculpture, proposing critical questions regarding social issues, sparking attention and discussion among viewers to achieve social care and participation.

The impact and contribution of this study on experimental instruction will be as follows:

1. Through this course, a site for teaching and local implementation will be constructed in which students may be free from the constraints and thought processes of exhibitions (shows) of art museums, galleries, auditoriums, etc. With questioning at its core spirit, Interrogative Design is a way for people to participate in society through Mobile Graffiti Projection Mapping.
2. Interrogative Design is a cross-disciplinary course combining design, light projection, action vehicle production, and critical thinking. It trains students to gain deep understanding of local issues and to question through critical thinking. It attempts to teach students cross-domain integration, systematic thinking, and comprehensive practical skills.

3. This course guides students to pathways for alternative thinking and practice, enhancing the interaction between the university and the local community, establishing a symbiotic link between the school and the community, and teaching students how to play the role of a social citizen. It creates an opportunity for universities, teachers and students to dive into local issues, and actively participate in and practice "University Social Responsibility."

4. This study will gradually construct a "strategy of interrogative design" within the context of Taiwan's social history, which helps to expand the exploration of artistic practice and deepen related research.

\section{References}

[1] K. Wodiczko, Critical Vehicles: Writings, Projects, Interviews. Massachusetts Institute of Technology Press, 1999, pp. 16-17.

[2] Please refer to MIT website (http://web.mit.edu/idw/).

[3] D. Maniello, Augmented reality in public spaces: basic techniques for video mapping Volume 1 English edition. Edizioni Le Penseur. pp. 15-16.

[4] S. Linebaugh, Interactive Motion Graphics in a Live Environment:

Technology and Humanity. Faculty of the Motion Media Department in Partial Fulfillment of the Requirements for the Degree of Master of Fine Arts in Motion Media Design at Savannah

College of Art and Design, pp. 23-24.

[5] M. Naimark, "Two unusual projection spaces," Presence: Teleoperators and Virtual Environments, Vol. 14, no. 5, 2005, pp.

597-605.

[6] R. Raskar, G. Welch, et al. "The office of the future: A unified approach to image-based modeling and spatially immersive displays," SIGGRAPH' 98 Proceedings of the 25th annual conference on Computer graphics and interactive techniques. ACM

NY, USA, 1998, pp. 179-188.

[7] O. Bimber, A. Emmerling and T. Klemmer "Embedded Entertainment With Smart Projectors," IEE Computer Society. Vol.

38,no. 1, 2005, pp. 48-55.

[8] E. Ferrance, Themes in Education: Action Research. The Education

Alliance: Brown Heinemann. 2000, pp. 4-5.

[9] J. McNiff, with J. Whitehead, Action Research: Principles and Practice. Taylor \& Francis. 2002, pp. 40. 